\title{
Sacrococcygeal Joint
}

National Cancer Institute

\section{Source}

National Cancer Institute. Sacrococcygeal Joint. NCI Thesaurus. Code C33506.

The amphiarthrodial joint between the sacrum and coccyx. 